\title{
What behind Coronavirus? How Coronavirus affect the Economic Growth
}

Nisreen Mousa*

$\mathrm{PhD}$ Student in the Field of Economics

DOI: $10.36348 /$ sjef.2020.v04i04.002

| Received: 14.04 .2020 | Accepted: 21.04 .2020 | Published: 24.04 .2020

*Corresponding author: Nisreen Mousa

\section{Abstract}

The first occurrence of the highly contagious Coronavirus was in 2003 when China was hit with the Severe Acute Respiratory Syndrome coronavirus (SARS-COV). SARS resulted in around 8,000 infections and 774 deaths worldwide not to mention the impact on world economy which saw declines in domestic and international travel and over 40 billion dollars in economic losses. Fast-forward to 2012, Saudi Arabia was hit with novel Middle East Respiratory Syndrome coronavirus (MERS COV) causing over 1611 active cases and 575 deaths worldwide. Since December 2019, our world succumbed to the rapid spread of COVID-19 now reaching 2,204,511 infections and 149,000 deaths worldwide. COVID19 virus spreads through droplets of spittle or nose flow when an infected person coughs or sneezes. Effects vary between mild respiratory difficulties with average patients to severe illness with older people and those with underlying medical problems. Since vaccines are still unavailable, the world were to adopt extraordinary measure to control the outbreak such as flight suspensions, visa restrictions, border closures, social distancing and quarantine. The effects on world economy were severe with huge losses in tourism, travel, retail and service sectors and strains on the medical sector due to high demand and treatment costs. The circumstances surrounding COVID-19's spread makes many inquire about the motives of governments that are benefiting from the high infection and mortality rate of this virus to unproductive people, elderly and people with chronic illnesses forming a huge burden on welfare systems. Finally, with nothing confirmed, it is important to inquire about the invisible hands behind the epidemic and what would wait the world after COVID-19.

Keywords: Coronavirus Economic Growth SARS.

Copyright @ 2020: This is an open-access article distributed under the terms of the Creative Commons Attribution license which permits unrestricted use, distribution, and reproduction in any medium for non-commercial use (NonCommercial, or CC-BY-NC) provided the original author and source are credited.

\section{What is coronavirus and what could be behind it}

2003 was the year in which Coronavirus shocked the world by its high malevolence and active spread among humans, known as Severe Acute Respiratory Syndrome coronavirus (SARS-COV) in which china was the first country that embraces the virus that year. More than 8,000 patients were infected worldwide, resulting in 774 deaths. As a result, SARS affected the world economy negatively so that the domestic demand and international travel has been declined, and the world economic loss has been estimated to be 40 billion dollars. In April 2012, a novel Middle East Respiratory Syndrome coronavirus (MERS $\mathrm{COV}$ ) was identified instantly after SARS coronavirus and was known as "human beta-coronavirus 2c EMC/2012 and human coronavirus EMC (HCoVEMC)", which has caused genetical infections in humans. Actually, Coronaviruses belong to the RNA virus family eligible to spread disease in humans and animals. They are classified into four species based on their protein sequences differences. "HCoV-229E and HCoV-NL63 belong to Alphacoronavirus. HCoV-
OC43 and HCoV-HKU1 belong to lineage A Betacoronavirus, while SARS-CoV and MERS-CoV belong to lineages $\mathrm{B}$ and $\mathrm{C}$ Betacoronavirus, respectively". Both SARS-CoV and MERS-CoV are phylogenetically closely related to coronaviruses in bats $[1,2]$. Moreover, "Middle East respiratory syndrome (MERS)", was first announced in Saudi Arabia in 2012, and became a serious threat to world health safety, such as Ebola or swine flu. Between March 2012 and $1^{\text {st }}$ November 2015, the World Health Organization (WHO) declared 1611 active cases and 575 deaths worldwide. MERS inflow countries include Saudi Arabia (1255 cases and 539 deaths), South Korea (185 cases and 36 deaths) and the United Arab Emirates (81 cases and 11 deaths)[3].

Therefore, did Coronavirus treated that period or continued to come in waves? Unfortunately, our world is influenced by epidemics and the rapid spread of the disease starts to appear through COV-19 as people try to make reasonable efforts to avoid infection and apply the appropriate measures taken by authorities 
in trying to control the outbreak. According to WHO (World Health Organization) Coronavirus disease (COVID-19) is a newly discovered coronavirus that lead to an infectious disease. COVID-19 virus affects people differently. Those who experience mild to moderate respiratory illness recover without requiring special treatment. Older people, especially those with underlying medical problems like cardiovascular disease, diabetes, chronic respiratory disease, and cancer are more likely to develop serious illness.
Nowadays, on $28^{\text {th }}$ of March 2020, the total global number of COVID-19 cases has exceeded (500 000 and about 23,335 deaths), western pacific region $(100,018$ cases and 3,567deaths), European Region (286,697 cases and 16,105 deaths), South-East Asia Region (2,932 cases and 105 deaths), Eastern Mediterranean Region (35,249 cases and 2,336 deaths), Region of the Americas (81,137 cases and 1,176 deaths) and African Region (2,419 cases and 39 deaths).

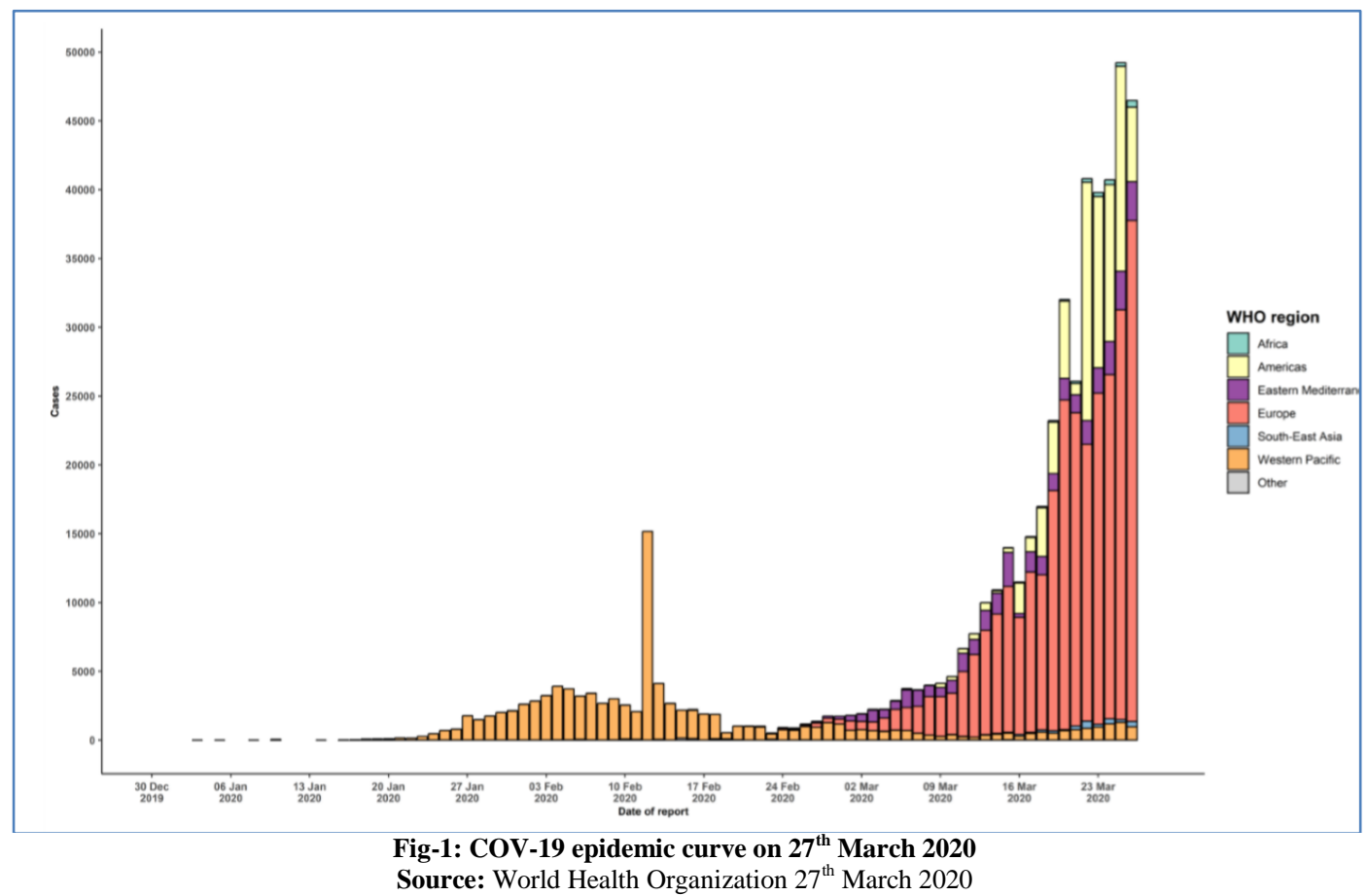

Consequently, countries try to implement specific measures in order to control the outbreak of the virus, particularly COVID-19 virus spreads mostly through droplets of spittle or from nose flow as long as an infected person coughs or sneezes. Hence, countries execute a variety of health measures in cooperation with member states, the United Nations, the aviation and tourism sector including refusal of entry "of passengers from countries experiencing outbreaks, followed by flight suspensions, visa restrictions, border closures, and quarantine measures [4]". Moreover, and because vaccine or specific treatments are still unavailable, it is important to implement rules of isolation in order to prevent the healthy people from being infected by injured population [5].

All of these arise questions of who is behind the virus? how does COVID-19 affect the world economy? And so many more questions.

On December 31 of last year, Chinese authorities warned the World Health Organization (WHO) of an outburst of a novel genealogy of coronavirus leading to a severe illness, which was then named SARS-CoV-2 (SARS COVID-19). On $20^{\text {th }}$
February 2020, about 167,500 COVID-19 cases have been confirmed, although many more mild cases have likely gone undiagnosed. The virus has led to over 6,600 deaths in Wuhan. After the epidemic began, the Chinese authority declared that the number of injured cases has been increasing due to the rapid spread of the virus mainly through human to human transmission. Consequently, after two month the virus outbreak Wuhan to spread in whole china and 33 countries. On $24^{\text {th }}$ of February 2020, "accumulative 77,658 confirmed cases with 9,126 severe cases and 2,663 deaths were documented in China, and 2,309 confirmed cased with 33 death were reported in other countries (including Japan, Korea, Italy, Singapore, Iran as the top five countries) $[6,4,7,]^{\prime}$.

Going back for a while, Wuhan includes the most important laboratories regarding research on the most dangerous pathogens. The plan was to build "between five and seven biosafety level-4 (BSL-4) labs across the Chinese mainland by 2025", which arise the fear about pathogens spreading between china and the world. Thus, the emergence of such viruses especially that transfer from animals to humans (SARS or Ebola) was a concern and a vital issue for the Chinese scientist 
as Bruno Lina, director of the VirPath virology lab in Lyon, France mentioned. Thus, the escape of SARS virus (the main cause of MERS virus) during inclusion in Beijing multiple times, increase worries around the Chinese lab [8].

In 2003, scientists in Wuhan's Chinese laboratories were able to reactivate a frozen virus inside an animal cell that was part of a group of fossils found on the borders of the Chinese province of Hubei. This event shocked the scientific community because of the great danger that it may carry.

In 2003, in Wuhan, China, the virus was reactivated to study it closely and learn its effects on the human gene. Contrary to what scientists believed and contrary to its classification within the coronavirus family, scientists discovered that the virus attacks binary code cells. This meant that the virus is genetically modified through a process of self-evolution to attack the binary code cells - the cells that the human body begins to form after the age of 60 years especially those elderly people that suffer serious chronic diseases. In other words, and as Falsey and Frederick [9] in their study about Rhinovirus and Coronavirus InfectionAssociated Hospitalizations among Older Adults found that all patients with a mean age of 74 years that were infected by Coronavirus family suffered a serious chronic diseases "Consistent with the high rate of lung disease, $92 \%$ were active or previous smokers, 33\% took corticosteroids daily, and $50 \%$ received oxygen at home".

COVID-19: this is the name given to this deadly virus at the time, in remembrance of the COVID-18 virus that attacked the human race.

It is thus important to inquire about the primary aim for this disease. Is there any intention of getting rid of unproductive people, the elderly and people with chronic diseases?

Nothing is confirmed yet, but in economic view the capitalist world is getting rid of everything that burdens its budget, which is already suffering from a slowing global economy, the Epoch Times published a report today stating that 21 million phones were disconnected from the network in China within 3 months, which indicates the true death toll in China. The opposing Chinese millionaire in Taiwan, "Cheng Won", known as "Zach", spoke about the fact that in Wuhan alone; more than 39,000 people die every day, unlike other Chinese provinces and cities. At the same time, a sudden and strange decision was taken to evacuate all European citizens from China, especially those residing in the city of Wuhan, at the height of the spread in China in February 2020. This meant that tens of thousands of people suspected of contracting the virus would return to Europe and the United States.
According to the Italian Ministry of Finance, the typical Italian citizen after the age of sixty benefits from a pension, social security and welfare services which cost the government 280,000 euros every year. This amount increases at a rate of $1.3 \%$ on average every year. Moreover, Italy is a country with an aging population in which $27 \%$ of Italy's 61 million people are over the age of 60 (about 16.5 million old people). Similarly, 22\% of Spain's 46 million people are elderly (around 10.5 million old people), and 20\% of France's 67 million people are elderly (around 13.4 million old people). These statistics do not even account for patients with chronic illnesses who are unable to work and are thus entitled to monthly welfare support.

Can anyone picture the huge budgets that are spent on them every year? Italy announced the collapse of its health system. Spain as well, Norway reported only 800 cases, and then announced that their health system had been decommissioned, Sweden as well, Denmark and Finland. The United States announced a state of emergency - something that did not happen even in the darkest days of their hostility with the Soviet Union in the 1960s!! and Each of these saves 280,000 euros out of the state annual budget. Italy announced that the number of deaths is nearing the 4,500 cases, which means 1.26 billion euros every year.

\section{The economic impact of Coronavirus}

Studies on Coronavirus impact still under researched although most studies reflect the economic loss associated with industrial sector like tourism and retail service sector but the medical cost associated with the disease, such as expenditures on identifying and treating the disease grow up by the need to preserve sterile environments, execute precaution measures, and manage fundamental research. According to Wha Lee and McKibbin [10] stated that "the costs of disease also include income forgone as a result of disease-related morbidity and mortality". Declined income is associated by the workdays lost due to the illness. In the case of mortality, declined income is associated by the "value of future lifetime earnings lost to the disease related death".

Barro and Sala-I-Martin [11] mentioned that according to the neoclassical growth models the negative impact to population growth can lead to a more capital accumulation and hence higher output growth. On the contrary, an exogenous reduction in labour force lead to a high capital/labour ratio and a low return to capital rate, which consequently leads to decrease capital accumulation and then lower output growth. In addition, the decline in "health capital," as measured in general by life expectancy, affects economic growth negatively [12]. Moreover, and according to the precautions implemented to control the outbreak of the virus including the prohibition of labours from moving across the region within the 
country or across countries affect labour productivity negatively.

The outbreak of Coronavirus leads to the decline of consumer demand especially in travel and service sectors. Such an epidemic makes people fear from being interacted socially mainly in the affected regions. Thus, regions that have high density of population and high service activities suffered the most from the demand shock such as China and such an outbreak prevailed in all over the world through the international travel. Moreover, and as china was the center of foreign investment and as the disease reverberates through China, the response by the Chinese government to the epidemic was blurry and nontransparent, the thing that arise questions regarding the quality of Chinese institutions. Therefore, the loss of confidence by foreign investors even if it is difficult to know the investors decision making would have a negative impact of Chinese economic growth and in turn affect other countries output growth especially those competitors for FDI "Foreign Direct Investment".

Finally, details still blurry and nothing is confirmed regarding the formation and target of Coronavirus. Thus, it is important to inquire about the invisible hands behind the epidemic and to be aware of what next, which mean what would wait the world after Corona.

\section{REFERENCES}

1. To, K. K., Hung, I. F., Chan, J. F., \& Yuen, K. Y. (2013). From SARS coronavirus to novel animal and human coronaviruses. Journal of thoracic disease, 5(Suppl 2), S103.

2. Stephens, G. M., Woo, P. C., Zaki, A. M., Memish, M., Perlman, S., Poon, L. L., ... \& Brown, S. (2013). Middle East Respiratory Syndrome. J. Virol, 87(14), 7790.

3. Kim, K. H., Tandi, T. E., Choi, J. W., Moon, J. M., \& Kim, M. S. (2017). Middle East respiratory syndrome coronavirus (MERS-CoV) outbreak in South Korea, 2015: epidemiology, characteristics and public health implications. Journal of Hospital Infection, 95(2), 207-213.

4. WHO.(2020). Clinical management of severe acute respiratory infection when novel coronavirus (nCoV) infection is suspected: interim guidance. Jan 11, 2020.

5. Ai, T., Yang, Z., Hou, H., Zhan, C., Chen, C., Lv, W., \& Xia, L. (2020). Correlation of chest CT and RT-PCR testing in coronavirus disease 2019 (COVID-19) in China: a report of 1014 cases. Radiology, 200642.

6. Xu, X. W., Wu, X. X., Jiang, X. G., Xu, K. J., Ying, L. J., Ma, C. L., \& Sheng, J. F. (2020). Clinical findings in a group of patients infected with the 2019 novel coronavirus (SARS-Cov-2) outside of Wuhan, China: retrospective case series. Bmj, 368.

7. National Health Commission of the People's Republic of China. http://www.nhc.gov.cn (Assessed on February 25th, 2020).

8. Cyranoski, D. (2017). Inside the Chinese lab poised to study world's most dangerous pathogens. Nature, 542(7642).

9. Falsey, A. R., Walsh, E. E., \& Hayden, F. G. (2002). Rhinovirus and coronavirus infectionassociated hospitalizations among older adults. The Journal of infectious diseases, 185(9), 1338-1341.

10. Lee, J. W., \& McKibbin, W. J. (2004, April). Estimating the global economic costs of SARS. In Learning from SARS: preparing for the next disease outbreak: workshop summary (p. 92). Washington, DC: National Academies Press.

11. Barro, R. J., \& Sala-i-Martin, X. (1995). Economic Growth McGraw-Hill. New York.

12. Bloom, D. E., Canning, D., \& Sevilla, J. (2001). The effect of health on economic growth: theory and evidence (No. w8587). National Bureau of Economic Research. 